\title{
A SIMPLIFIED METHOD FOR ESTIMATING CARBON MONOXIDE IN BLOOD WITH THE VOLUMETRIC VAN SLYKE APPARATUS
}

BY

\author{
J. W. NICHOLAS
}

From Silver End, Essex

(RECEIVED FOR PUBLICATION NOVEMBER 30, 1950)

The volumetric methods for the estimation of blood gases, for example, those of Van Slyke and Salvesen (1919), O'Brien and Parker (1922), Hawk, Oser, and Summerson (1947), are inferior in accuracy to the manometric, for example, that of Van Slyke and Neill (1924), but the simplicity and lower cost of the volumetric apparatus more than outweigh this disadvantage where the determination of carbon monoxide saturation for clinical purposes is required. The volumetric method, however, usually involves a number of difficulties which are especially troublesome to those who only use it occasionally; some of these difficulties also apply to the manometric. It is necessary, for example, for the carbon-dioxide-absorbent, and if carbon monoxide is to be measured by absorption the oxygen-absorbent as well, to be gas-free. It is difficult to determine when the vacuum extraction is complete, extraction to constant volume not being practicable owing to the lack of fine graduations above $1.0 \mathrm{ml}$. The extraction is in any case an equilibrium procedure, and the solution will ultimately be brought into equilibrium with an atmosphere whose pressure and composition vary with variations in the gases extracted ; allowance for this complicates the calculation or renders empirical corrections desirable. Most important of all, as there is no opportunity to clean out the apparatus during an estimation, traces of the original blood remain in the chamber and gas-burette and may cause precipitates with cuprous chloride or the reabsorption of $\mathrm{CO}$ when haemoglobin is re-formed by hydrosulphite. Scholander and Roughton (1942) have described a simplified micro-gasometric method for estimating $\mathrm{CO}$. This gives reasonably accurate results, the standard deviation of differences between their published results and determinations by Horvath and Roughton's (1942) manometric method being 0.93 , and replicate determinations always being within $2 \%$ CO-saturation of each other. As, however, corrections are left to balance themselves, it must be considered as an empirical method and greater reliance placed on more orthodox Van Slyke techniques. Harington and Van Slyke (1924) have modified the chamber of the manometric apparatus, thus allowing it to be washed out during a determination and so enabling cuprous chloride to be introduced without causing precipitates. Van Slyke and Robscheit-Robbins (1927) have also described a method for the determination of $\mathrm{CO}$ using this modification. The alteration consists of the addition of an extra bulb, stopcock, and exit tube below 
the chamber. Its construction will be beyond the capabilities of many laboratories, and it does not avoid the exposure of solutions to a greatly reduced pressure between the absorption processes.

My purpose is to describe a simple attachment to the volumetric Van Slyke apparatus, which can be made by any technician, and which will permit gases to be ejected from and returned quantitatively to the chamber. It is therefore possible to wash the latter out at any time, and as the extracted gases need never be reduced appreciably below atmospheric pressure there is no need for absorbing solutions to be rendered gas-free. The method is presented as reasonably accurate and rapid, but above all as a reliable and convenient technique, which will give dependable results in the hands of a worker only occasionally having to use it.

\section{Apparatus and Materials}

A bulb is blown in a piece of 2-mm. bore manometer tubing having a capacity of about the same as the greatest volume of blood sample it is proposed to use (i.e., $2 \mathrm{ml}$., or for special purposes $5 \mathrm{ml}$.). This tubing is bent at the top and attached to the bent capillary of the Van Slyke (Fig. 1). Its lower end dips vertically into a large, thick-walled test-tube containing mercury, and the tube and bulb are themselves filled with mercury before an analysis. It is obviously preferable that the joint should be a fused one, but failing this it may be made with translucent polyvinyl chloride ("P.V.C.") tubing, the glass ends being brought as closely into apposition as possible. P.V.C., unlike rubber, tubing has the advantages of being nonporous and of permitting air-bubbles to be seen through it. It should be stated, however, that in practice no trouble from the retention of air-bubbles at the joint has been encountered, and that all results recorded in this paper were obtained with an apparatus with a P.V.C. joint. If an apparatus is being specially constructed it should be noted that the modification renders the two limbs below the lower stopcock superfluous, and that the tubing connexion can be placed immediately below a single-bore stopcock. The use of P.V.C. tubing for connecting the levelling bulb should render the use of a Shohl air-trap unnecessary.

FIG. 1.-Modification applied to standard Van Slyke volumetric apparatus. (In a specially constructed apparatus the two limbs below the lower cock could be eliminated.)

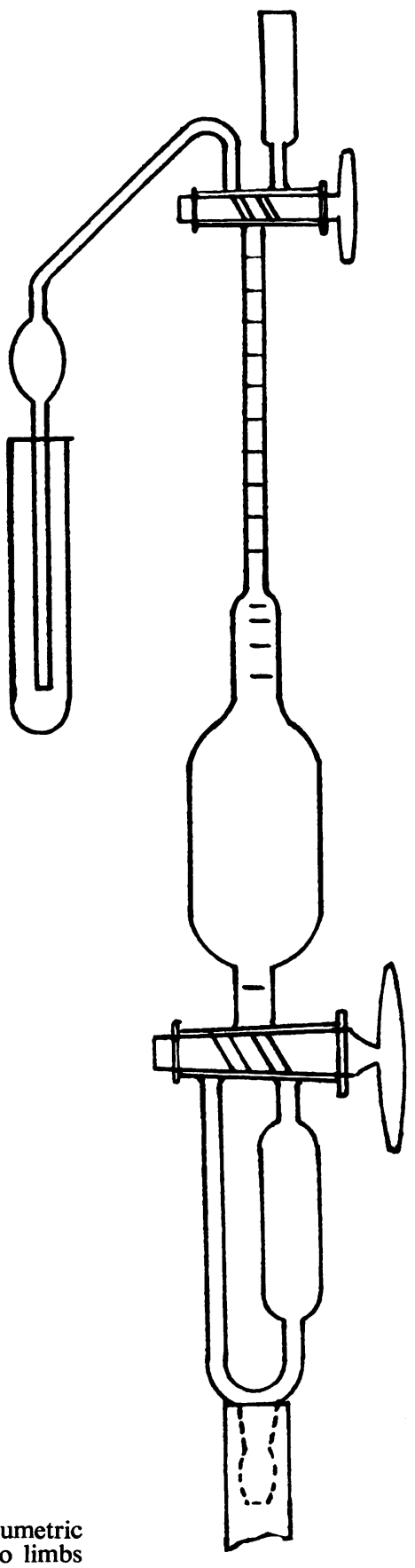


The whole apparatus is rigidly supported on a steel retort stand, the base of which is clamped to the bench. Agitation is performed by maintaining a rotary vibration of the $\frac{1}{2}$-in. rod of the stand, which will swirl the solution over the chamber walls without throwing mercury out of the test-tube. The use of a silicone* grease for lubricating stopcocks is strongly recommended, as it eliminates all difficulties arising from organic greases being attacked by the strong alkalis used. It is also recommended for greasing the stoppers of the reagent bottles containing the alkaline absorbing solutions.

If measurements in terms of volumes per cent are required Ostwald-Van Slyke pipettes are used for measuring the blood. These are tipped, not with the shaped piece of thick rubber tubing usually recommended, but with a thin unshaped piece of tubing ( $4 \mathrm{~mm}$. diameter, $2 \mathrm{~mm}$. bore) which takes the shape of the tip of the pipette and fits snugly in the mouth of the capillary below the cup. If results are required as percentage saturation, less precision is of course necessary in measuring the sample, as its volume will only enter into the calculation of the correction for dissolved oxygen. Here an $8 \%$ error in the volume of blood will only make a difference of $0.001 \mathrm{ml}$. to the correction. Ordinary pipettes can therefore be used so long as care is taken that no air follows the blood into the chamber.

Reagents.-The following are required.

(1) Acid Ferricyanide.-This is described by Hawk et al. (1947).

$\begin{array}{lcccccccr}\text { Saponin } & \ldots & \ldots & \ldots & \ldots & \ldots & \ldots & \ldots & 3.0 \mathrm{~g} . \\ \text { Potassium ferricyanide } & \ldots & \ldots & \ldots & \ldots & \ldots & \ldots & 8.0 \mathrm{~g} . \\ \text { Lactic acid } & \ldots & \ldots & \ldots & \ldots & \ldots & \ldots & \ldots & 4.0 \mathrm{ml} \text {. } \\ \text { Capryl alcohol } & \ldots & \ldots & \ldots & \ldots & \ldots & \ldots & \ldots & 3.0 \mathrm{ml} \text {. } \\ \text { Distilled water to } & . & \ldots & \ldots & \ldots & \ldots & \ldots & \ldots & 1,000 \mathrm{ml} \text {. }\end{array}$

The reagent should be shaken before use. It is stable for several weeks.

(2) Potassium Hydroxide (approximately N).

(3) Potassium Hydroxide (approximately 4N).

(4) Hydrosulphite Reagent.-This is made up as follows:

Sodium hydrosulphite $\left(\begin{array}{llllll}\left.\mathrm{Na}_{2} \mathrm{~S}_{2} \mathrm{O}_{4}\right) & \ldots & \ldots & \ldots & \ldots & 5.0 \mathrm{~g} .\end{array}\right.$

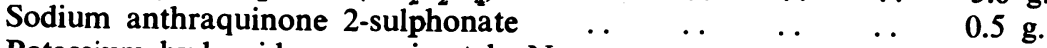
Potassium hydroxide approximately $\mathbf{N}$.

This should be made, with the minimum exposure of the solution to the air, in the bottle in which it is to be stored. It is stable in a well-stoppered bottle for about a week. When the colour changes from red to yellow it should be discarded.

(5) Ammoniacal Cuprous Chloride.-This contains the following:

$\begin{array}{llllllllr}\text { Cuprous chloride } & . & \ldots & \ldots & \ldots & \ldots & \ldots & \ldots & 40 \mathrm{~g} \text {. } \\ \text { Ammonium chloride } . . & \ldots & \ldots & \ldots & \ldots & \ldots & \ldots & 50 \mathrm{~g} . \\ \text { Distilled water to } & . & \ldots & \ldots & \ldots & \ldots & \ldots & \ldots & 150 \mathrm{ml} \text {. } \\ \text { Ammonia (S.G. 0.9) } & \ldots & \ldots & \ldots & \ldots & \ldots & \ldots & \ldots & 50 \mathrm{ml} \text {. }\end{array}$

The reagent should be stored in a well-stoppered bottle over copper wire, when it will be stable for several weeks.

(6) Ammonia, approximately $3 \mathrm{~N}$.

(7) Lactic acid, approximately $\mathrm{N}$.

* For example, Dow-Corning stopcock grease, supplied in England through Messrs. W. Edwards and Co. (London), Ltd. 


\section{Procedure}

The apparatus is first rinsed out with the ferricyanide reagent. Then $6 \mathrm{ml}$. of reagent is introduced into the chamber and extracted repeatedly until gas-free, the gases being ejected via the cup after each extraction. The blood sample (usually $2 \mathrm{ml}$.) is then introduced under $1 \mathrm{ml}$. of mercury in the cup, and is extracted repeatedly until no more gas is evolved, extracted gases being passed into the side-tube after each extraction. After ejection of the blood via the cup the gas burette and chamber are washed out with $\mathrm{N} \mathrm{KOH} ; 0.58 \mathrm{ml}$. $4 \mathrm{~N} \mathrm{KOH}$ are introduced into the burette, and the gases returned. The fluid level is lowered repeatedly to about the $1.5-\mathrm{ml}$. mark until no further absorption of carbon dioxide takes place; the volume of oxygen plus carbon monoxide plus nitrogen is then read over the $\mathrm{KOH}$ column, allowing for the density of the latter in levelling as mentioned below. Readings are made with a lens, with a good light behind the burette, interpolating to $0.001 \mathrm{ml}$. The gases are then returned to the side-tube and the $\mathrm{KOH}$ ejected via the cup. Hydrosulphite reagent, $0.58 \mathrm{ml}$., is run into the burette, gases returned for absorption of oxygen, and the volume of carbon monoxide plus nitrogen read over the reagent column as before. The remaining gases are again returned to the side-tube, and the reagent ejected via the cup. The burette and entry to the side-tube are washed twice with water, and $0.58 \mathrm{ml}$. of cuprous chloride introduced into the former. Gases are returned for absorption of $\mathrm{CO}$, and the volume of residual nitrogen read over the reagent. Finally the apparatus is cleaned and prepared for the next determination by washing out both chamber and side-tube with dilute ammonia, followed by $\mathrm{N}$ lactic acid. All absorptions are rapid, and take only a minute or two.

It should be noted that although normally control of the rate of flow of either a gas or liquid is exercised by the bottom (mercury) cock, and the top one is used only to determine the direction, rather different considerations obtain when it is desired to expel the last traces of gas from the side-tube into the burette. Here the flow of mercury should be interrupted suddenly by means of the top cock, before the gas has time to rise through it.

The absorbent solutions used are of approximately the same density, and their volume is adjusted so that provided the mercury meniscus is not below $1.0 \mathrm{ml}$. it is only necessary to hold the levelling bulb at a graduation $0.05 \mathrm{ml}$. higher to allow for the weight of the column of reagent. If the mercury should be in the wider part of the burette it is necessary either to estimate $1 / 11.5$ of the aqueous column, or to eject the latter before reading. In the determination of CO-saturation it is unnecessary to correct for temperature or barometric pressure so long as these have remained constant throughout the analysis, the $\mathrm{CO}$-saturation being calculated as:

$$
\text { Volume of } \mathrm{CO} \times 100 /\left(\text { Volume of } \mathrm{CO}+\text { Volume of combined } \mathrm{O}_{2}\right. \text { ) }
$$

If results are required in volumes per cent the usual corrections must, of course, be applied.

\section{Correction for Dissolved Gases}

O'Brien and Parker have shown that the correction for carbon monoxide in physical solution is negligible. The blood will, however, be saturated with oxygen. Allowing an absorption coefficient of 0.031 for oxygen at $20^{\circ} \mathrm{C}$., a factor of 0.92 for the fact that whole blood is used instead of water, $20.9 \%$ for the oxygen content of the air, $760 \mathrm{~mm}$. for the barometric pressure, and $20^{\circ} \mathrm{C}$. for the temperature, the volume of oxygen in solution in $2 \mathrm{ml}$. of blood will be $0.013 \mathrm{ml}$. (measured moist); this value should therefore be subtracted from the measured volume of oxygen. Variation in this correction with temperature is slight (Table I), and variation with barometric pressure is negligible. 
TABLE I

CORRECTION FOR DISSOLVED OXYGEN*

\begin{tabular}{|c|c|c|c|c|}
\hline Temperature $\left({ }^{\circ} \mathrm{C}.\right)$ & 15 & 20 & 25 & 30 \\
\hline Dissolved $\mathrm{O}_{2}$ (ml.) & 0.014 & 0.013 & 0.012 & 0.012 \\
\hline
\end{tabular}

${ }^{*}$ Blood samples were of $2 \mathrm{ml}$.

\section{Precision and Accuracy}

A specimen of oxalated human venous blood was divided into two parts. One of these was shaken with carbon monoxide, and after bubbles of gas had been dispersed was mixed with the other part and allowed to stand for 24 hours in a closed container to ensure that cells, plasma, and gas phase were in equilibrium. No attempt was made to obtain solutions of known saturation owing to the difficulty of fully saturating whole blood and the possibility of introducing excess of $\mathrm{CO}$ in physical solution. Samples, each of $2 \mathrm{ml}$., were analysed by the method described, with the results given in Table II. It will be observed that the standard deviation is $0.6 \% \mathrm{CO} \mathrm{Hb}$.

TABLE II

REPRODUCIBILITY (REPLICATE DETERMINATIONS)

\begin{tabular}{|c|c|c|c|}
\hline Experiment & $\underset{(\mathrm{ml} .)}{\mathrm{CO}}$ & $\mathrm{CO}(\mathrm{ml})$. & $\underset{(\%)}{\text { CO Saturation }}$ \\
\hline $\begin{array}{l}1 \\
2 \\
3 \\
4 \\
5 \\
6\end{array}$ & $\begin{array}{l}0.451 \\
0.426 \\
0.446 \\
0.438 \\
0.438 \\
0.431\end{array}$ & $\begin{array}{l}0.075 \\
0.075 \\
0.080 \\
0.080 \\
0.075 \\
0.079\end{array}$ & $\begin{array}{l}16 \cdot 6 \\
17 \cdot 6 \\
17 \cdot 9 \\
17 \cdot 7 \\
17 \cdot 1 \\
18 \cdot 3\end{array}$ \\
\hline & & $\begin{array}{r}\text { Mean } \\
\text { Standard deviation }\end{array}$ & $\begin{array}{r}17 \cdot 5 \\
0 \cdot 6\end{array}$ \\
\hline
\end{tabular}

Ten other partially saturated blood samples were prepared in a similar manner and analysed by the present method and an abridged spectrophotometric method (Nicholas, in press); the range of saturation covered was $14-52 \%$. The mean difference between results was $0.19 \% \mathrm{CO} \mathrm{Hb}$, with a standard deviation about this mean of $0.69 \%$. Results will be given in full in the reference cited. With two methods so entirely different in principle it is highly improbable that any extraneous factor can have affected both equally, and therefore each can be used as a measure of the reliability of the other. It can therefore be assumed that the standard deviation of either method taken alone does not exceed $0.69 \% \mathrm{CO} \mathrm{Hb}$, and it is more probable that the errors will be divided between the two methods, giving, if the division is equal, a standard deviation for each of $0.69 / \sqrt{ } 2=0.49 \% \mathrm{CO} \mathrm{Hb}$.

From the foregoing the possible error of the method can be considered as of the order of $\pm 1.0 \%$ saturation $(2 \times$ S.D. $)$. This compares favourably with Van 
Slyke and Salvesen's figures, from which a mean deviation from expectation of $0.77 \%$ saturation and a standard deviation about this mean of $1.33 \%$ saturation can be calculated. It is possible that some of their error may be accounted for by unavoidable inaccuracy in the preparation of the blood mixtures, but in the two cases where they did duplicate estimations they obtained differences of $0.9 \%$ and $2.2 \%$ saturation.

\section{Summary}

A modification of the Van Slyke volumetric apparatus is described which provides storage space for gases, thus enabling the chamber and gas burette to be washed out in the course of an estimation, and dispensing with the exposure of gasabsorbing reagents to a vacuum ; the latter do not, therefore, require to be gas-free. The modification of the apparatus can be carried out in any laboratory.

A method is described for the estimation of carbon monoxide using this apparatus, which can be considered as accurate to $\pm 1.0 \% \mathrm{CO}$ saturation.

\section{REFERENCES}

Harington, C. R., and Van Slyke, D. D. (1924). J. biol. Chem., 61, 575.

Hawk, P. B., Oser, B. L., and Summerson, W. H. (1947). Practical Physiological Chemistry, 12th ed., p. 639. London.

Horvath, S. M., and Roughton, F. J. W. (1942). J. biol. Chem., 144, 747.

Nicholas, J. W. In the press.

O'Brien, H. R., and Parker, W. L. (1922). J. biol. Chem., 50, 289.

Scholander, P. F., and Roughton, F. J. W. (1942). J. industr. Hyg., 24, 218.

Van Slyke, D. D., and Neill, J. M. (1924). J. biol. Chem., 61, 523.

Van Slyke, Robscheit-Robbins, F. S. (1927). Ibid., 72, 39.

— and Salvesen, H. A. (1919). Ibid., 40, 103. 